\title{
ENJOY FFD
}

\author{
Blanco Lorenzo, Enrique M. ${ }^{1}$; Garcia-Requejo, Zaida² \\ ${ }^{1}$ Universidade da Coruña, ETS de Arquitectura, \\ 0000-0002-8456-9100 \\ ${ }^{2}$ Universidade da Coruña, ETS de Arquitectura, \\ 0000-0003-4743-815X
}

\section{RESUMO}

Dende a materia Fundamentals of Fashion Design (FFD) de primeiro curso e primeiro cuadrimestre do Grao en Xestión Industrial da Moda da UDC aspiramos a que o desfrute do alumnado sexa unha ferramenta eficaz cada acadar as competencias establecidas. Cun perfil que se achega aos estudos dende a visión empresarial, as materias que afondan nas problemáticas do deseño precisan dun impulso para captar a súa atención e interese, afondando na importancia da coherencia entre 0 pensamento e 0 deseño. Nas tres primeiras edicións do grao tense utilizado 0 xogo de rol como estratexia para fomentar a implicación, de xeito que coas de denominacións Ferrol Fashion Show, Premier e Gala, propuxéronse actividades grupais que a garantisen. Consistiron en asumir 0 rol de empresa de moda que se ocupa do lanzamento dunha colección ou dunha película histórica, así como no deseño dunha gala virtual. Desenvolvéronse hibridando actividades individuais, para a construción dun booklet persoal, e grupais para acadar unha presentación final de curso, a modo de gran evento colectivo estendido por todos os espazos da facultade físicos ou virtuais, que se converteu no obxectivo e fito principal do curso. 0 proceso demostrouse útil e eficaz, aos efectos de acadar os obxectivos previstos.

PALABRAS CLAVE: Fundamentals of Fashion Design, Grao en Xestión Industrial da Moda, innovación docente, xogo de rol, deseño 


\section{CITA RECOMENDADA:}

Blanco Lorenzo, Enrique M.; Garcia-Requejo, Zaida (2021): Enjoy FFD. En García Naya, J.A. (ed.) (2021). Contextos universitarios transformadores: a nova normalidade académica. Leccións aprendidas e retos de futuro. V Xornadas de Innovación Docente. Cufie. Universidade da Coruña. A Coruña (pág. $67-79)$

DOI capítulo: https://doi.org/10.17979/spudc. 9788497498180.067

DOl libro: https://doi.org/10.17979/spudc. 9788497498180

\section{ABSTRACT}

From the subject Fundamentals of Fashion Design (FFD), first year first term of the Degree in Fashion Industry Management of the UDC we aspire the enjoyment of the student is an effective tool to achieve the established competencies. With a profile that approaches to studies from a business vision, the subjects working under the design world need an impulse to catch their attention and interest, handling in the importance of the coherence between thought and design deepening the importance of coherence between thoughts and design. In the first three editions of the degree the role game has been used as a strategy to promote their commitment, so entitled Ferrol Fashion Show, Premier and Gala, group activities have been proposed to guaranteed it. They consisted of assuming the role of a fashion company that deals with the launch of a collection or a historical film, or the design of a virtual gala. They developed works hybridizing individual activities, for the construction of a personal booklet, and group commissions to achieve a final presentation, as a large collective event extended by all the physical or virtual spaces, which became the main objective and milestone of the course. The process has been tested useful and effective, in order to achieve the planned objectives.

KEY WORDS: Fundamentals of Fashion Design, Degree in Fashion Industry Management, teaching innovation, role playing game, design 


\section{INTRODUCCIÓN}

0 Grao en Xestión Industrial de la Moda céntrase na adquisición de competencias relacionadas coa xestión en tódolos eslavóns da cadea da industria da moda. As materias, divididas en catro cursos académicos, encáixanse en módulos que conteñen dende temáticas relacionadas coa xestión empresarial, a enxeñaría de procesos e sistemas de información ou responsabilidade social empresarial, até 0 deseño e a moda. Este último módulo, ao que pertencen tan só 0 vinte un por cento dos créditos totais do grado, arranca coa materia Fundamentals of Fashion Design (FFD), en primeiro curso, primeiro cuadrimestre.

FFD é unha materia destinada a dar a coñecer os conceptos básicos do deseño e os seus principios universais, así como a introducir vínculos cos ámbitos da arte e a moda. A materia pertence á area de coñecemento de Composición Arquitectónica da Escola Técnica Superior de Arquitectura da Coruña, e é impartida por dous profesores, Enrique M. Blanco Lorenzo e Zaida García Requejo, que teñen formación de arquitecto. Tras ela, a área ten docencia en tres materias máis, distribuídas nos tres seguintes cuadrimestres da titulación, que son Debuxo e Expresión Gráfica Aplicados á Moda, Deseño de Moda, e Estilismo, Estética e Patronaxe.

A materia FFD conta cunha carga de 6 créditos ECTS, con horas divididas en docencia expositiva e interactiva, correspondentes a sesións maxistrais e sesións en taller respectivamente. Nas sesións maxistrais, os dous arquitectos docentes realizan exposicións orais sobre o contido teórico da materia, que se complementan co emprego de medios audiovisuais, coa finalidade de transmitir ao alumnado as bases fundamentais dos contidos e facilitar a súa aprendizaxe. En ocasións, estas clases teóricas se substitúen por seminarios a cargo de profesionais do sector, que contribúen ao achegamento da experiencia profesional real á aula. ${ }^{1}$ Durante as horas de taller, búscase a aplicación de aprendizaxes nas que sexa posible combinar diferentes metodoloxías - exposicións, simulacións, debates, solución de

1 Durante os tres anos de rodaxe da materia, téñese contado, entre outros invitados, coa colaboración da arquitecta e deseñadora Tania Campos. Esta invitación intencionada buscar facer ver ao alumando como de preto se atopan os fundamentos de ramas do deseño aparentemente tan separadas coma son a arquitectura e a moda. 
problemas, etc. -, aplicación a través das que 0 alumnado desenvolve tarefas eminentemente prácticas sobre un tema específico, co apoio e supervisión do profesorado. Como complemento a estas clases expositivas e interactivas, e co obxectivo de promover a aprendizaxe autónoma e grupal, o alumnado desenvolve traballos prácticos de tipo analítico en diversos formatos: por unha banda, un traballo individual semanal relacionado coa temática vista durante a semana nas sesións presenciais, e, por outra banda e a partir da metade do curso, un traballo grupal. A modo de estímulo e provocación, emprégase como lema da materia en todos os enunciados e presentación: be "Smart + pro". Os traballos individuais, cuxa única condición de deseño é que se realicen en formato A3 por unha cara, compílanse ao final do curso nun booklet individual (Figura 1), permitindo aos estudantes amosar as competencias adquiridas ao longo do cuadrimestre.

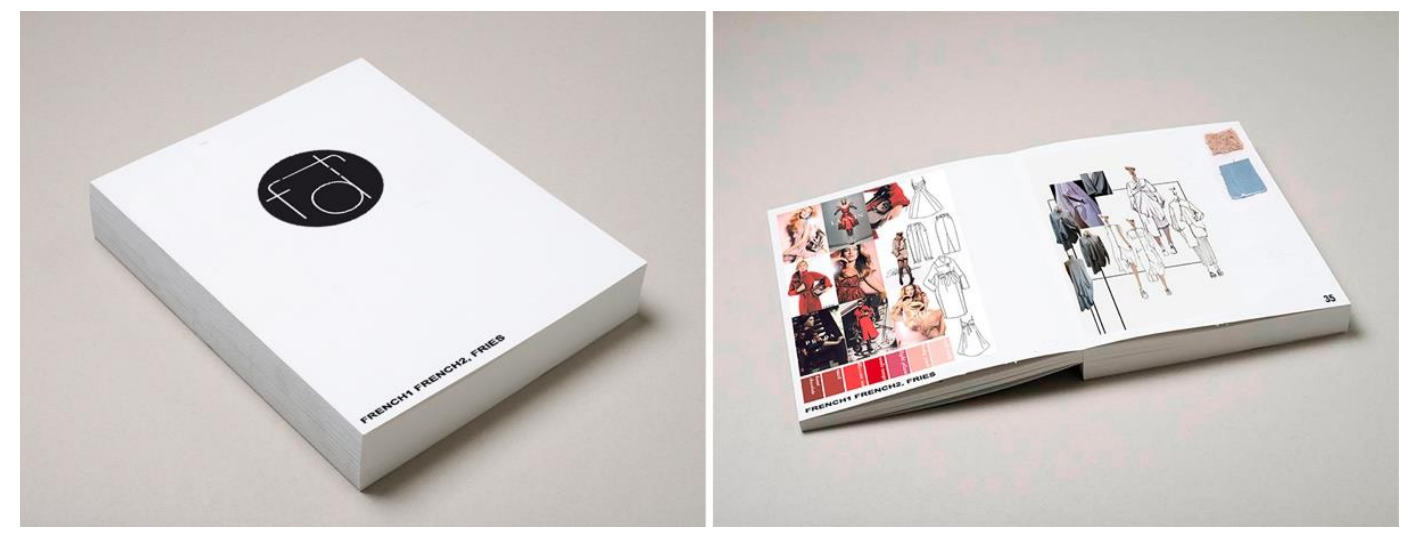

Figura 1. Exemplo de formalización do booklet individual da materia FFD.

0 traballo grupal, que constitúe 0 eixo central desta comunicación, busca sempre acadar os mesmos obxectivos, a través da aplicación da metodoloxía do xogo de rol, pero variando a temática curso tras curso coa intención de sorprender aos estudantes. Os obxectivos deste traballo grupal son, por unha banda, facer entender ao alumnado dun grao centrado na xestión, a relevancia do deseño e o papel do deseñador e, por outra, facer desfrutar ao alumnado para xerar entusiasmo, situándoo no centro de toda actividade docente. Ademais, 0 
desenvolvemento deste traballo grupal contribúe a acadar outros dous obxectivos da materia, como son dominar os fundamentos do deseño, enmarcándoos no seu contexto particular e xeral, e desenvolver as necesarias habilidades para a xeración de ideas creativas. As indicacións semanais para o desenvolvemento de ambos traballos, individuais e grupal, compártense co alumnado empregando, ademais da ferramenta institucional do campus virtual, dúas canles: o blog da materia e o seu perfil de Instagram (Figura 2).

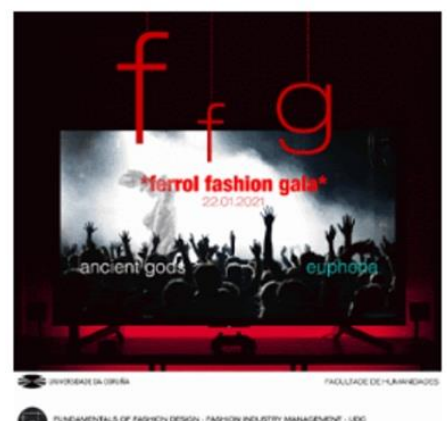

TEAMWORK PRESENTATION - FERROI FASHION GALA [ONLINE] mors was a cennest

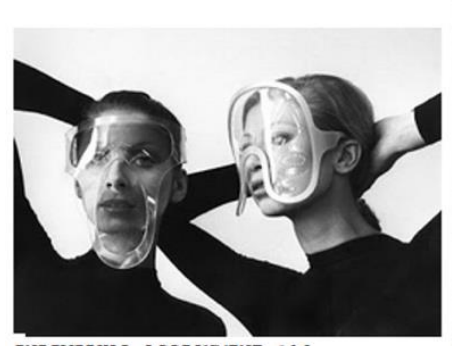

INDIVIDUAL ASSIGNMENT \#06

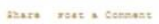

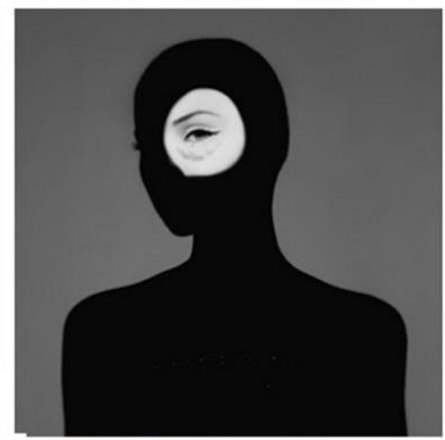
INDIVIDUAL ASSIGNVENT $\nRightarrow 07$ TNDIVIDUAL

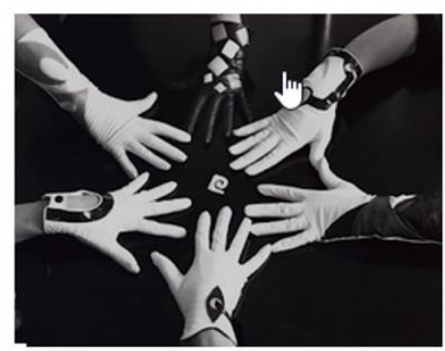

TEAM WORK $\# 04$. TIMELINE IEAT WORK \$OS
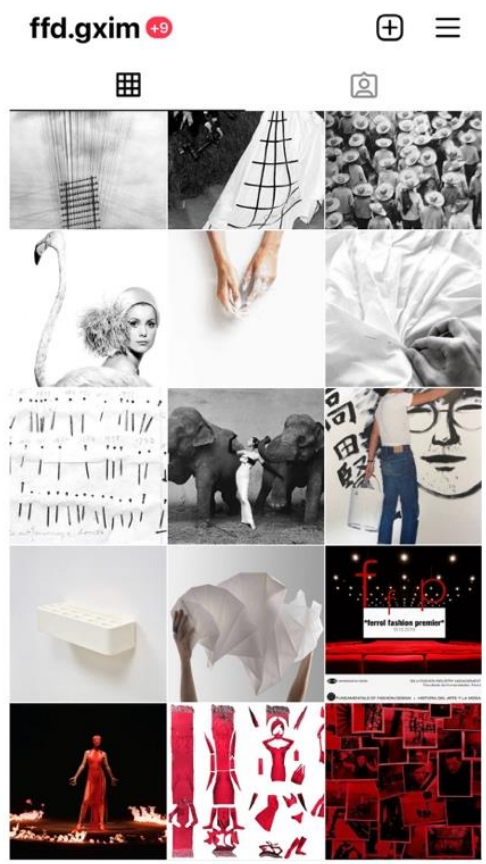

๙

Figura 2. Ferramentas dixitais empregadas na materia FFD.

0 resultado do traballo grupal desenvolto nos dous primeiros cursos, nos que ademais 0 traballo individual desenvolveuse en colaboración coa materia Historia da Arte e da Moda, avalan a eficacia da aplicación do "xogo de rol" no que o alumnado desenvolve o papel dun profesional ao que se lle fai un encargo concreto. Estas dúas experiencias consistiron no 
lanzamento dunha colección de moda de temática histórica no curso 2018/2019, e 0 desenvolvemento da vestimenta dunha película histórica no curso 2019/2020 (Figura 3).

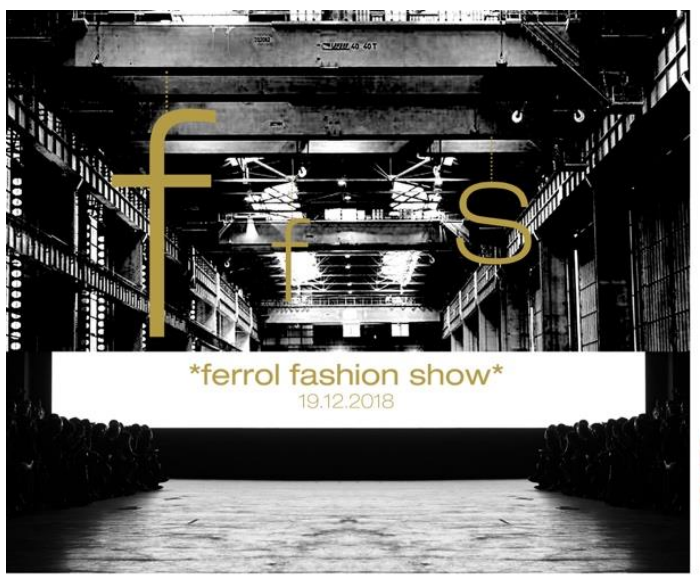

$§$ UNIERSIDADE DA CORURA Facultade de Humanidades. Ferrol

FUNDAMENTALS OF FASHION DESIGN + HISTORIA DEL ARTE Y LA MODA

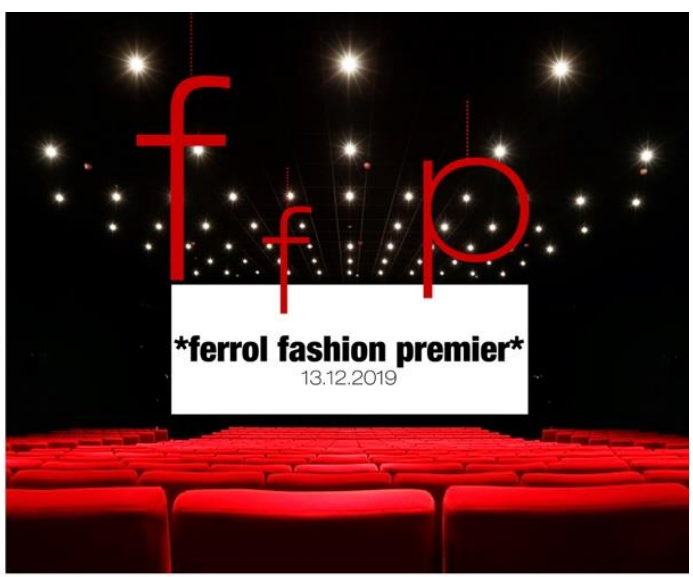

$§$ UNIVERSIDADE DA CORURA

BA in FASHION INDUSTRY MANAGEMENT Facultade de Humanidades. Ferrol

Fundamentals of Fashion design + historia del ARTE y La MODA

Figura 3. Carteis dos eventos Ferrol Fashion Show e Ferrol Fashion Premier, decembro de 2018 e decembro do 2019, respectivamente.

No presente curso académico 2021/21, coas limitacións existentes derivadas da crise sanitaria, o reto era aínda maior: a planificación dun evento de moda coñecido como é a Gala MET, que debía desenvolverse necesariamente de maneira telemática.

\section{DESCRICIÓN DA EXPERIENCIA}

0 desenvolvemento do traballo grupal é obrigatorio para todo 0 alumnado da materia, coa excepción daqueles estudantes matriculados a tempo parcial con dispensa académica de exención de asistencia. Os grupos de traballo son elaborados polos propios estudantes, coa limitación de ter que pertencer ao mesmo grupo de docencia interactiva, de xeito que sexa posible traballar xuntos durante as horas de clase. Ademais das fontes documentais principais da materia, que serven tanto como complemento das sesións maxistrais como de axuda no desenvolvemento das tarefas individuais e grupal, tómanse como referencia aquelas 
experiencias levadas a cabo noutras escolas de deseño que deron lugar a resultados de calidade, tales como as experimentadas na Central Saint Martins ou na ETH de Zurich. ${ }^{2}$

Nun primeiro momento, propuxéronse dúas alternativas aos estudantes para a conformación dos grupos: ben facer seis grupos de máis membros, ou doce grupos de menos membros cada un, desenvolvendo dúas temáticas de traballo diferentes. Seguindo as súas preferencias, configuráronse catro equipos en cada subgrupo de docencia interactiva, sumando un total de doce equipos. 0 encargo consistía en planificar 0 evento da Gala MET, dividindo as funcións en seis aspectos da celebración: alfombra vermella, exposición, cena de gala, espectáculos, Vogue edición papel e difusión en redes sociais. Por tanto, tendo doce equipos e seis tarefas, foi necesario desenvolver dúas temáticas diferentes, é dicir, dúas Galas MET que se celebraron o mesmo día - o pasado mércores 13 de xaneiro -, unha a continuación da outra, a través da plataforma Teams. A elección destas temáticas tamén se deixou nas máns do alumnado, buscando sempre potenciar a ilusión, permitíndolles traballar sobre un tema que lles interese. Cada grupo de estudantes podía propoñer unha temática, que posteriormente se votou a través da aplicación menti. Así, as dúas máis votadas, e por tanto seleccionadas para a celebración do evento dobre, foron "Ancient Gods" e "Euphoria Aesthetics".

2 Alexander, L., y Meara, T. (2019). Central Saint Martins Foundation: Keay lessons in art and design. Hachette UK; Spiro, A., y Kluge, F. (2018). How to Begin?: Architecture and Construction in Annette Spiro's First-Year Course, ETH Zurich. University of Chicago Press. 


\section{Your favourite theme [group work]}

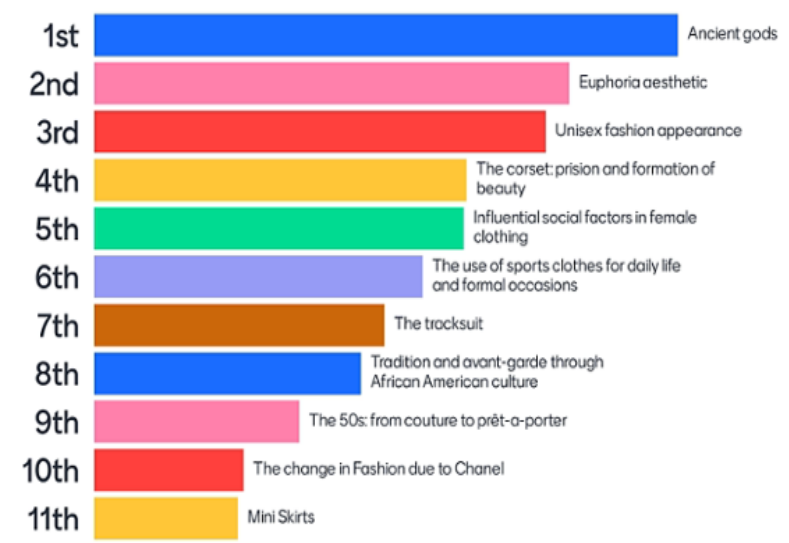

Figura 4. Votación das temáticas para a celebración da Gala MET.

0 desenvolvemento deste traballo grupal comeza a mediados do cuadrimestre, normalmente a partir da semana sete de curso, e, durante as diferentes semanas, o profesorado vai facendo diferentes "encargos" aos grupos. Estes encargos parciais non se configuran coma obxectos materiais, senón como fases do desenvolvemento que guían a cada grupo no proceso de organización do evento. 0 primeiro paso consistiu na recompilación de información - 0 tema, outras galas, etc. -, o segundo paso pasou por escoller ao axentes implicados en cada unha das tarefas - os deseñadores a cargo da alfombra vermella, os deseños expostos en cada unha das exposicións, os cociñeiros encargados do menú, os artistas que configuran o cartel dos espectáculos, os contidos que conforman a edición de Vogue ou o que se difunde en cada unha das redes sociais -, para, posteriormente, deseñar os obxectos que se empregan en cada un dos casos durante o espectáculo final. Nun primeiro momento, os estudantes atópanse desorientados, ao considerar que non posúen nin as instrucións nin as ferramentas necesarias para afrontar o encargo. Como representar unha alfombra vermella sen invitados e sen deseños? Como deseñar unha exposición sen ter os obxectos a exhibir? Que menú ten que ter unha cena virtual? Que tipo de actuación se propón sen grupos ou cantantes? Como deseñar unha revista sen material? E como se lle conta isto ao mundo a través das redes? Ese é o reto! 
Noutras palabras, os estudantes deben de empregar os fundamentos básicos de deseño de xeito creativo, atopando a maneira de sobrepoñerse a estas carencias.

\section{RESULTADOS}

Os resultados desta experiencia déronse a coñecer no momento de celebración da Ferrol Fashion Gala a través da plataforma Teams, o pasado mes de xaneiro. A gala contaba cos dous docentes da materia como presentadores, caracterizados como tal e ambientados no exterior e no interior do Museo Metropolitano de Arte de Nova lork empregando a opción de fondo que ofrece a ferramenta, e deron entrada ás dúas temáticas, Ancient Gods primeiro, Euphoria Aesthetics despois (Figura 5).
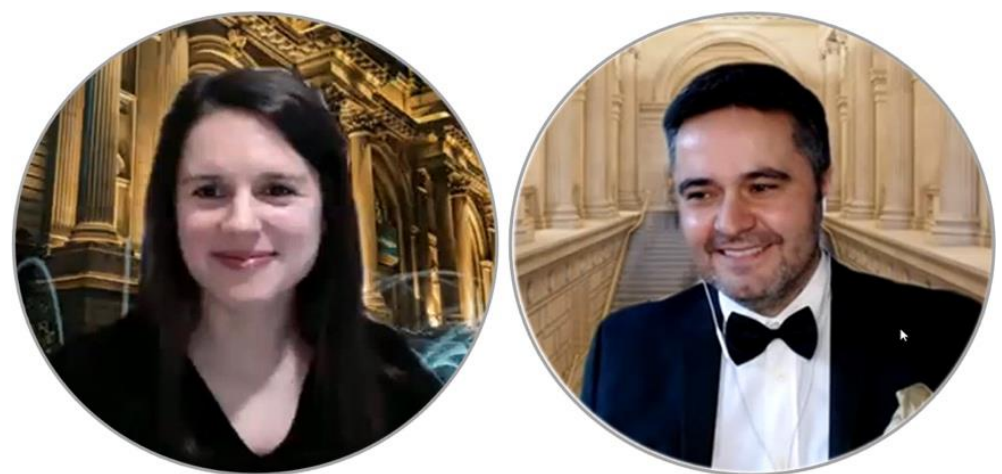

Figura 5. Zaida García Requejo e Enrique M. Blanco Lorenzo, caracterizados como presentadores da Gala MET, situados no exterior e no interior do Museo Metropolitano de Arte de Nova lork, a través do emprego da ferramenta Teams.

Con respecto ás experiencias anteriores, o desenvolvemento da Ferrol Fashion Gala implicaba unha dificultade engadida: cada unha das temáticas conformaba un único evento, polo que os integrantes dos equipos non só debían amosar os deseños e ideas creativas parciais que compoñían o seu traballo, senón que os seis grupos que desenvolvían cada unha das temáticas debían acordar como conducir a gala, polo que todos eses deseños e enfoques debían necesariamente gardar algunha relación. As indicacións por parte do profesorado tan so marcaban os límites da actuación de cada grupo por separado, que debían ter unha 
duración de entre 8 e 12 minutos en total, pero non se limitaba o número de intervencións nos que esgotar dita duración. Deste xeito, a valoración dos resultados inclúe a capacidade de relacionar 0 deseño conceptual realizado por cada grupo co espazo temporal total da gala e 0 resultado de conxunto.

En ámbolos dous casos, Ancient Gods e Euphoria Aesthetics, os diferentes grupos orquestraron a secuencia do evento de xeito fluído, alternando as diferentes actividades, sen limitarse a seguir a orde preestablecida - alfombra vermella, exposicións, menú, espectáculos, revista física e redes sociais -. Esta estratexia de alternancia permite evidenciar a coherencia temática, indo máis alá dos bos resultados acadados en cada unha das facetas do evento por separado. Estes resultados aínda están dispoñibles nas redes sociais de cada unha das temáticas, a través da consulta das contas propias de Instagram e Twitter, que empregaron non só para compartir material ou promocionar o evento, senón tamén para implicar ao profesorado, tanto da materia de FFD como do resto das materias do cuadrimestre (Figura 6).
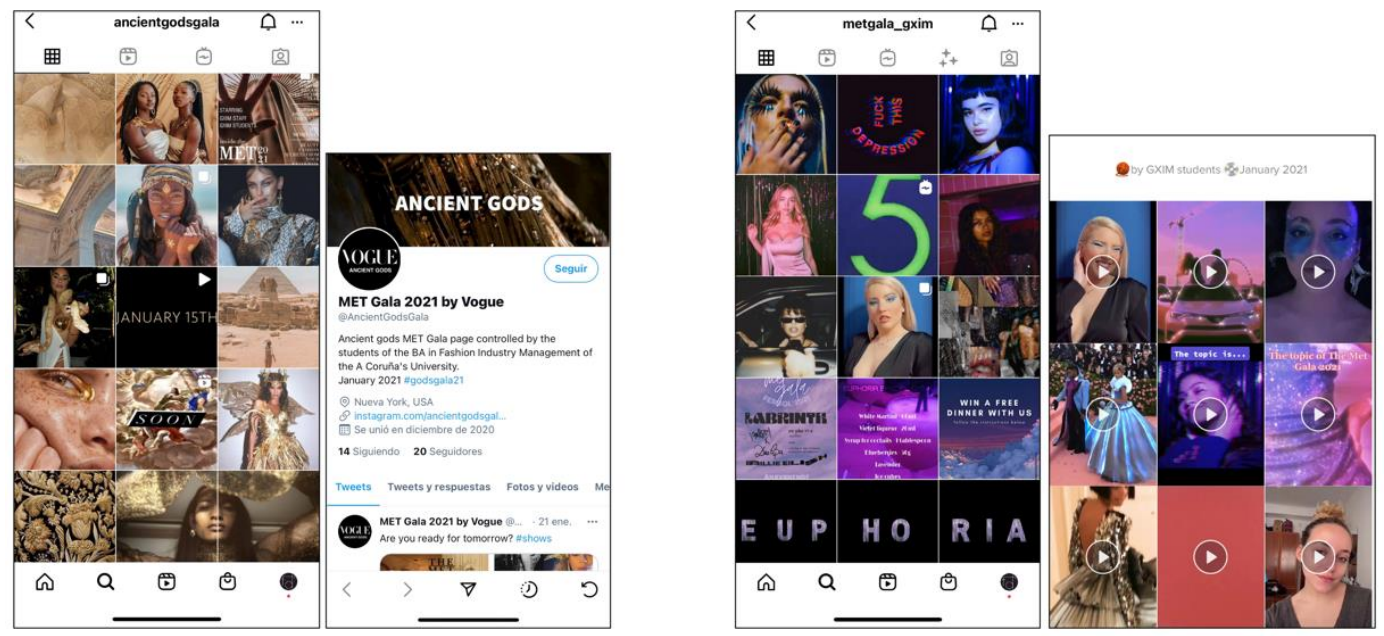

Figura 6. Contas de Instagram e Twitter das dúas temáticas da Gala MET, Ancient Gods e Euphoria Aesthetics.

Os resultados parciais de cada unha das facetas a desenvolver dentro das temáticas foron variadas, incluso a pesar de que cada temática tiña que desenvolver as mesmas seis tarefa. 
Por citar un exemplo, no caso da alfombra vermella, mentres a temática de Ancient Gods realizou unha serie de píldoras audiovisuais de inspiración que compartiron en redes e puxeron á disposición un filtro propio de Instagram no que invitaban a tódolos participantes a compartir unha story coa única limitación de levar posto algo dourado, a temática de Euphoria Aesthetics elaborou unhas guías audiovisuais que permitían aos invitados obter unha caracterización propia de cada un dos personaxes da serie de televisión.

\section{CONCLUSIÓNS}

Trala celebración de tres horas, os materiais producidos e amosados a modo de coreografía conxunta e o sorriso da foto grupal final funcionan, neste caso, a modo de conclusións... (Figura 7).

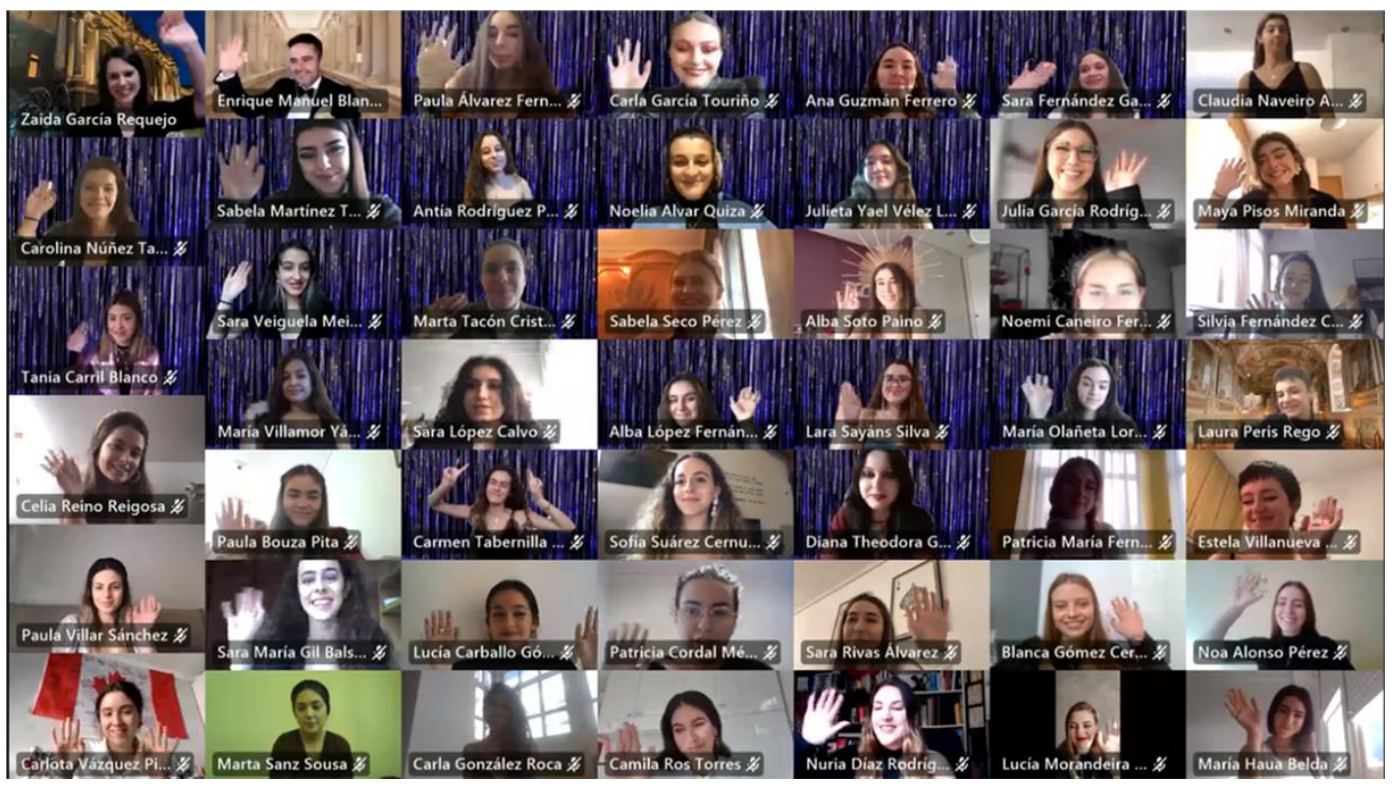

Figura 7. Foto final tomada a través da plataforma Teams trala celebración do evento Ferrol Fashion Gala.

0 empreso da estratexia do "xogo de rol" ven demostrando, nos últimos tres cursos, ter aplicación válida no ensino dunha materia destinada a guiar aos estudantes nos seus 
primeiros pasos no mundo do deseño. No caso particular do evento da Ferrol Fashion Gala levada a cabo no presente curso, o entusiasmo por ter que desenvolver un evento coñecido incrementa a produtividade e a implicación dos estudantes: saben en que consiste, coñecen exemplos, buscan referentes...todo iso coa intención de acadar uns resultados que estean á altura dun evento que coñecen e valoran. Do mesmo xeito, as diferentes temáticas desenvoltas durante os tres cursos amosan a versatilidade do método: 0 que importa é a credibilidade da situación. A complexidade engadida de ter que orquestrar un evento de xeito conxunto axuda a desenvolver as capacidades do alumnado de traballo en diferentes equipos, o grupo pequeno que desenvolve a tarefa, por unha banda, e, por outra, o conxunto de xente que colabora na organización dunha actividade ao completo.

Os bos resultados acadados e a satisfacción do alumnado tralo desenvolvemento do traballo, invitan a continuar testando esta experiencia do "xogo de rol" en cursos que están por vir. A modo de peche, pódese concluír que FFD preséntase como unha primeira materia de introdución ao deseño que pretende caracterizalos como axentes dun contexto real e motivador, ao que sexan capaces de enfrontarse xuntos, como o farán algún día no mundo profesional.

\section{REFERENCIAS}

Aicher, 0. (1994). El mundo como proyecto. Gustavo Gili.

Alexander, L., y Meara, T. (2019). Central Saint Martins Foundation: Keay lessons in art and design. Hachette UK.

De Fusco, R. (2005). Historia del diseño. Santa \& Cole.

Díaz Sánchez, J. (2012). Arte, diseño y moda: confluencias en el sistema artístico. Ediciones de la Universidad de Castilla-La Mancha.

Elam, K. (2014). La geometría del diseño: estudios sobre la proporción y la composición. Gustavo Gili.

Loewy, R. (1983). Lo feo no se vende. Editorial Iberia S.A. 
Munari, B. (2006). ¿Cómo nacen los objetos? Gustavo Gili.

Munari, B. (2008). Design as art. Penguin modern classics.

Press, M. (2009). El diseño como experiencia. Gustavo Gili.

Souriau, E. (1990). Diccionario Akal de Estética. Ediciones Akal.

Sparke, P. (2010). Diseño y cultura, una introducción. Gustavo Gili.

Spiro, A., y Kluge, F. (2018). How to Begin?: Architecture and Construction in Annette Spiro's First-Year Course, ETH Zurich. University of Chicago Press.

Volpintesta, L. (2015). Fundamentos del diseño de moda: los 26 principios que todo diseñador de moda debe conocer. Promopress.

Wong. W. (2011). Fundamentos del diseño. Gustavo Gili. 
